\title{
Benefit-risk assessment of golimumab in the treatment of refractory ulcerative colitis
}

\author{
This article was published in the following Dove Press journal: \\ Drug, Healthcare and Patient Safety \\ 3 February 2016 \\ Number of times this article has been viewed
}

\author{
Daniela Pugliese \\ Carla Felice \\ Rosario Landi \\ Alfredo Papa \\ Luisa Guidi \\ Alessandro Armuzzi \\ Inflammatory Bowel Disease Unit, \\ Complesso Integrato Columbus, \\ Catholic University, Rome, Italy
}

Correspondence: Alessandro Armuzzi Inflammatory Bowel Disease Unit, Complesso Integrato Columbus, Catholic University, Via Giuseppe Moscati 31, 00168 Rome, Italy Tel +39063503357

Email alearmuzzi@yahoo.com

\begin{abstract}
Significant advances in the management of patients with ulcerative colitis (UC) have been made since the introduction of anti-tumor necrosis factor (TNF)-alpha agents, especially for those who fail or do not tolerate conventional therapies. Two drugs, infliximab first, then adalimumab afterward, showed effectiveness in inducing and maintaining long-term remission both in pivotal trials as well as in clinical practice. However, approximately $25 \%$ of patients with $\mathrm{UC}$, who fail or do not tolerate all available therapies, require a colectomy for refractory disease. The therapeutic scenario of UC has been recently upgraded by the introduction of golimumab, the latest anti TNF-alpha agent to be approved. Golimumab is a totally humanized monoclonal antibody, administered by a subcutaneous injection every 4 weeks. Treatment with golimumab has shown to be effective to induce sustained clinical benefit in tough-to-treat patients with UC, including steroid and/or immunosuppressive refractory and steroid-dependent patients. In this review, we summarize all available efficacy and safety data of golimumab in UC, analyzing the potential therapeutic position for the treatment of refractory patients with UC.
\end{abstract}

Keywords: ulcerative colitis, refractoriness, anti-TNF-alpha, golimumab

\section{Introduction}

Since the introduction of anti-tumor necrosis factor (TNF)-alpha drugs approximately 15 years ago, the management of ulcerative colitis (UC) has dramatically changed. Initially used only for severe steroid-refractory active diseases as "the last chance" before colectomy, ${ }^{1,2}$ over the years anti-TNF-alpha agents have been increasingly recommended in different categories of patients for inducing and maintaining clinical and endoscopic remission. ${ }^{3}$ To date, three anti-TNF-alpha drugs are licensed for the treatment of UC: infliximab, adalimumab, and recently golimumab. The mechanism of action of these drugs has been linked to the ability to bind both free-and surface bound anti-TNF-alpha on activated T lymphocytes, leading to their apoptosis. ${ }^{4}$

Infliximab, the first anti-TNF-alpha agent to be licensed for UC, is a mouse-human chimeric antibody, and is administered intravenously according to a scheduled regimen: one infusion at 0, 2, and 6 weeks, and every 8 weeks thereafter. ${ }^{5}$ In ACT 1 and ACT 2 pivotal trials, ${ }^{6}$ patients with moderately to severely active UC, despite the use of conventional therapies, naïve to anti-TNF-alpha, were treated with scheduled infliximab (at dosage of 5 or $10 \mathrm{mg} / \mathrm{kg}$ ) or placebo (ACT 1 for 46 weeks and ACT 2 for 22 weeks), and then followed-up for a further 8 weeks. In both studies, clinical response was statistically in favor of infliximab at both week 8 and 30. Furthermore, by week 30, in ACT 1 approximately $35 \%$ and in ACT 2 approximately $31 \%$ of patients receiving infliximab experienced clinical remission compared to $15.7 \%$ and $10.6 \%$ of the placebo groups,

submit your manuscript | www.dovepress.com 
respectively. A significant difference between infliximab and placebo treatment arms, with respect to maintenance of clinical remission, was also recorded at week 54 in ACT 1 study with approximately $34 \%$ vs $16.5 \%$, respectively, ${ }^{6}$ (Table 1). Long-term clinical practice data supported the effectiveness of infliximab in an outpatient setting with steroid- or immunomodulator-refractory patients with UC, with $68 \%$ showing sustained clinical remission during a median followup of more than 30 months. $^{7}$ Moreover, a significant benefit of scheduled treatment with infliximab has been shown in steroid-dependent patients with UC, with approximately $50 \%$ of patients achieving steroid-free clinical remission after 12 months $^{8}$ and $65 \%$ of whom maintained a durable clinical response after a median follow-up of 45 months. ${ }^{9}$

The therapeutic scenario of refractory patients with UC has been upgraded by the approval of adalimumab. Compared to infliximab, adalimumab has two peculiar characteristics: a fully humanized nature, which reduces the probability of infusion reactions and a subcutaneous (SC) self-administration. The standard regimen consists of an induction phase with 160/80 mg at week 0/2, respectively, and a maintenance phase with $40 \mathrm{mg}$ every other week. ${ }^{10}$ Adalimumab has been licensed after the publication of trials ULTRA 1 and ULTRA 2, enrolling patients with moderately to severely active disease despite stable doses of conventional drugs, who were either naïve or previously exposed to anti-TNF-alpha. ${ }^{11,12}$ Patients receiving adalimumab were significantly more likely to be in clinical remission compared to patients treated with placebo, with a therapeutic gain over placebo of $7.2 \%$ to $9.3 \%$ at week $8^{11,12}$ and of $8.8 \%$ at week $52^{12}$ (Table 1). An Italian observational study, including the largest case-series of patients with UC treated with adalimumab, has confirmed the effectiveness in the induction of durable clinical remission in patients with medically refractory UC. ${ }^{13}$

However, in both clinical trials and in population cohort studies including inflammatory bowel disease patients, anti-TNF-alpha treatment failures, categorized as primary nonresponse and secondary loss of response, were reported between $10 \%-40 \%$, and $20 \%-60 \%$ of cases, respectively. ${ }^{14,15}$ Dose intensification, empirically or based on therapeutic drug monitoring, or addition of other immunosuppressive drugs could represent effective strategies in order to manage secondary nonresponse. In case of failure of these options or in case of primary nonresponse, switching to another anti-TNF-alpha drug could be attempted. ${ }^{14,15}$ Unfortunately, to date, approximately $25 \%$ of patients with UC, who fail or do not tolerate all available therapies, will require colectomy for refractory disease. ${ }^{16}$

While waiting for new classes of drugs, golimumab, a new member of the anti-TNF-alpha family, has shown encouraging results in the treatment of refractory UC. ${ }^{17-19}$

This review summarizes all available efficacy and safety data of golimumab in UC and analyzes its therapeutic position for the treatment of refractory patients with UC.

\section{Golimumab}

Golimumab is a totally humanized anti-TNF-alpha monoclonal antibody, administered through SC injections. As with infliximab and adalimumab, golimumab blocks soluble and trans-membrane TNF-alpha, avoiding permanent TNFalpha receptor binding. However, compared to infliximab and adalimumab, golimumab preclinical studies showed greater conformational stability and higher binding affinity for soluble and trans-membrane TNF-alpha. ${ }^{20}$ The peak

Table I Summary of efficacy end points in pivotal trials with infliximab and adalimumab

\begin{tabular}{|c|c|c|c|c|c|c|c|c|}
\hline \multirow[t]{2}{*}{ Outcomes } & \multicolumn{5}{|l|}{ ACT $I^{6}$} & \multicolumn{3}{|l|}{ ACT $2^{6}$} \\
\hline & $\begin{array}{l}\text { IFX } 5 \mathrm{mg} / \mathrm{kg} \\
(\mathrm{n}=\mid 21) \mathrm{n}(\%) P^{a}\end{array}$ & \multicolumn{2}{|c|}{$\begin{array}{l}\text { IFX I0 mg/kg } \\
(n=122) \text { n (\%) } P^{a}\end{array}$} & \multicolumn{2}{|c|}{$\begin{array}{l}\text { Placebo } \\
(n=121) n(\%)\end{array}$} & $\begin{array}{l}\text { IFX } 5 \mathrm{mg} / \mathrm{kg} \\
(\mathrm{n}=12 \mathrm{I}) \mathrm{n}(\%) P^{\mathrm{a}}\end{array}$ & $\begin{array}{l}\text { IFX } 10 \mathrm{mg} / \mathrm{kg} \\
(\mathrm{n}=120) \mathrm{n}(\%) \mathrm{P}^{\mathrm{a}}\end{array}$ & $\begin{array}{l}\text { Placebo } \\
(n=123) n(\%)\end{array}$ \\
\hline Clinical response at week 8 & $84(64.9)<0.001$ & 76( & 5) $<0.001$ & $45(37$ & & $78(64.5)<0.001$ & $83(69.2)<0.001$ & $36(29.3)$ \\
\hline Clinical response at week 30 & $63(52.1)<0.001$ & 62( & 8) 0.002 & $36(29$ & & $57(47.1)<0.001$ & $72(60)<0.00$ I & $32(26)$ \\
\hline Clinical remission week 30 & $4 I$ I (33.9) $0.00 \mathrm{I}$ & 45( & 9) $<0.001$ & $19(15$ & & 31 (25.6) 0.003 & $43(35.8)<0.001$ & $13(10.6)$ \\
\hline \multirow[t]{3}{*}{ Clinical remission week 54} & $42(34.7) 0.001$ & 42( & 4) 0.001 & $20(16$ & & 1 & 1 & l \\
\hline & \multicolumn{5}{|l|}{ ULTRA I"I } & & \multicolumn{2}{|l|}{ ULTRA $2^{12}$} \\
\hline & \multicolumn{2}{|c|}{$\begin{array}{l}\text { ADA } 160 / 80 \mathrm{mg} \\
(\mathrm{n}=130) \mathrm{n}(\%) P^{\mathrm{a}}\end{array}$} & \multicolumn{2}{|c|}{$\begin{array}{l}\text { ADA } 80 / 40 \mathrm{mg} \\
(\mathrm{n}=130) \mathrm{n}(\%) P^{\mathrm{a}}\end{array}$} & \multicolumn{2}{|c|}{$\begin{array}{l}\text { Placebo } \\
(n=130) n(\%)\end{array}$} & $\begin{array}{l}\text { ADA } 160 / 80 \mathrm{mg} \\
(\mathrm{n}=248) \mathrm{n}(\%) P^{a}\end{array}$ & $\begin{array}{l}\text { Placebo } \\
(n=246) n(\%)\end{array}$ \\
\hline Clinical remission at week 8 & \multicolumn{2}{|c|}{$24(18.5) 0.031$} & \multicolumn{2}{|c|}{$13(10) 0.833$} & \multicolumn{2}{|c|}{$12(9.2)$} & $41(16.5) 0.019$ & $23(9.3)$ \\
\hline Clinical remission at week 52 & \multicolumn{2}{|l|}{1} & \multicolumn{2}{|c|}{1} & \multicolumn{2}{|c|}{1} & $43(17.3) 0.004$ & $21(8.5)$ \\
\hline Clinical response at week 8 & \multicolumn{2}{|l|}{$7 \mid(54.6)$} & \multicolumn{2}{|l|}{$67(5 \mid .5)$} & \multicolumn{2}{|c|}{$58(44.6)$} & $125(50.4) 0.001$ & $85(34.6)$ \\
\hline Clinical response at week 52 & \multicolumn{2}{|l|}{1} & \multicolumn{2}{|l|}{1} & \multicolumn{2}{|c|}{1} & 75 (30.2) 0.002 & $45(18.3)$ \\
\hline
\end{tabular}

Notes: aversus placebo. /, not applicable.

Abbreviations: IFX, infliximab; ADA, adalimumab. 
serum concentrations are reached within a maximum of 6 days (minimum 2 days) after a single administration of golimumab and the steady-state after approximately 14 weeks of scheduled treatment. The scheduled treatment for patients with UC comprises an induction phase with 200 and $100 \mathrm{mg}$ at week $0-2$, respectively, and a maintenance phase with 50 or $100 \mathrm{mg}$ every 4 weeks, according to patient's body weight ( $\geq$ or $<80 \mathrm{~kg}$, respectively) in Europe, and $100 \mathrm{mg}$ every 4 weeks in US. ${ }^{21}$ After the results of Program of Ulcerative Colitis Research Studies Utilizing an Investigational Treatment (PURSUIT), golimumab has been approved for the treatment of adult patients with moderately-to-severely active UC, who failed or not tolerated conventional drugs. This program comprises two induction studies PURSUIT-SC ${ }^{17}$ and PURSUIT-IV ${ }^{18}$ and one maintenance study, PURSUIT-M. ${ }^{19}$ Population enrolled included patients with moderately-to-severely active UC (defined as a Mayo Score of 6-12 with an endoscopic sub-score of at least 2), ${ }^{22}$ who showed steroid-dependence (defined as the inability to taper corticosteroids without recurrence of UC symptoms) or failed or not tolerated conventional therapies (including aminosalicylates, steroids, and thiopurines), naïve to anti-TNF-alpha.

\section{Induction studies}

The PURSUIT-SC trial, ${ }^{17}$ aimed at testing SC administration of golimumab, included two induction sub-studies: a Phase II dose-finding study to assess the best induction regimens (that would be used in the second study) and a Phase III to evaluate the efficacy and safety of previously selected golimumab induction dosages.
In the SC Phase II, three golimumab induction regimens were tested: 400 and $200 \mathrm{mg}, 200$ and $100 \mathrm{mg}$, and 100 and $50 \mathrm{mg}$ at week 0 and 2 , respectively. According to a dose-response proportional relationship recorded with greater changes of the Mayo Score from baseline and greater proportions of favorable clinical response and remission rate associated with higher serum golimumab exposure, the first two regimens were selected for the subsequent drug development.

In the SC phase 3,761 patients were randomized to receive one of two of the previously mentioned induction golimumab regimens or placebo. The primary endpoint was the proportion of patients achieving a clinical response at week 6 in each treatment arm. Clinical response was defined as a reduction in the full Mayo Score of at least 30\% and three points from baseline with either a decrease in the rectal bleeding sub-score $\geq 1$ from baseline or a rectal bleeding sub-score of 0 or 1 . At week 6 , clinical response was recorded in 51\% and 54.9\% of actively treated patients compared with $30.3 \%$ of the placebo group ( $P<0.0001$ for both comparisons), with a therapeutic gain of golimumab over placebo of approximately $20 \%$ (Table 2 ). Furthermore, at week 6 , patients who received golimumab were significantly more likely to achieve clinical remission and mucosal healing, to reduce $\mathrm{C}$-reactive protein (CRP) and improve their quality of life compared to those who received placebo. Clinical remission at week 6 (defined as a full Mayo Score $\leq 2$ with no individual sub-score $>1$ ) was achieved in $17.88 \%$ and $17.9 \%$ of patients who received golimumab at low and high dose regimens, respectively, compared to $6.4 \%$ of patients treated with placebo $(P<0.0001$ for both comparisons; Table 2). Complete endoscopic remission (Mayo

Table 2 Summary of efficacy endpoints in PURSUIT studies

\begin{tabular}{|c|c|c|c|c|}
\hline PURSUIT-SC'17 & $\begin{array}{l}\text { Golimumab } 200 / 100 \mathrm{mg} \text {, } \\
\mathrm{n}(\%)(\mathrm{n}=253)\end{array}$ & $\begin{array}{l}\text { Golimumab } 400 / 200 \mathrm{mg} \text {, } \\
n(\%)(n=257)\end{array}$ & $\begin{array}{l}\text { Placebo, n (\%) } \\
(n=25 I)\end{array}$ & $P$ \\
\hline Clinical response $^{\mathrm{a}}$ & $129(51)$ & $|4|(54.9)$ & $76(30.3)$ & $<0.000 \mathrm{I}^{\mathrm{b}}$ \\
\hline Clinical remission ${ }^{\mathrm{a}}$ & $45(17.8)$ & $46(17.9)$ & $16(6.4)$ & $<0.000 \mathrm{I}^{\mathrm{b}}$ \\
\hline Mucosal healinga & $107(42.3)$ & $116(45.1)$ & $72(28.7)$ & $\begin{array}{l}0.0014^{c} \\
<0.000 I^{d}\end{array}$ \\
\hline PURSUIT-M19 & $\begin{array}{l}\text { Golimumab } 100 \mathrm{mg} \text {, } \\
\text { n (\%) }(n=\mid 5 I)\end{array}$ & $\begin{array}{l}\text { Golimumab } 50 \mathrm{mg} \text {, } \\
\mathrm{n}(\%)(\mathrm{n}=\mathrm{I} \mathrm{I})\end{array}$ & $\begin{array}{l}\text { Placebo } n(\%) \\
(n=154)\end{array}$ & $P$ \\
\hline CCR & 75 (49.7) & 7I (47) & $48(3 \mid .2)$ & $\begin{array}{l}<0.00 \mathrm{I}^{\mathrm{e}} \\
0.010^{\mathrm{f}}\end{array}$ \\
\hline Clinical remission at both week 30 and 54 & $42(27.8)$ & $35(23.2)$ & $24(15.6)$ & $\begin{array}{l}0.004^{e} \\
0.122^{f}\end{array}$ \\
\hline Mucosal healing at both week 30 and 54 & $64(42.4)$ & $62(4 \mid .7)$ & $4 \mid(26.6)$ & $\begin{array}{l}0.002^{\mathrm{e}} \\
0.01 \mathrm{I}^{\mathrm{f}}\end{array}$ \\
\hline
\end{tabular}

Notes: ${ }^{a}$ At week 6 ; bor both comparisons; 'golimumab $200 / 100 \mathrm{mg}$ versus placebo; 'golimumab 400/200 mg versus placebo; 'golimumab I00 mg versus placebo; 'golimumab $50 \mathrm{mg}$ versus placebo.

Abbreviations: CCR, continuous clinical response; PURSUIT-SC, Program of Ulcerative Colitis Research Studies Utilizing an Investigational Treatment subcutaneous; PURSUIT-M, Program of Ulcerative Colitis Research Studies Utilizing an Investigational Treatment maintenance. 
endoscopy score of 0 or 1) rates were significantly higher than in controls: $42.3 \%$ and $45.1 \%$ in patients receiving golimumab $200 / 100$ and $400 / 200 \mathrm{mg}$ vs $28.7 \%(P=0.0014$ and $P<0.001$, respectively; Table 2). As CRP serum levels were significantly reduced from baseline in patients treated with golimumab at week 2 and 6 , respectively, on the contrary an increase of CRP levels was observed at both time-points in the placebo group. A remarkable difference between active and control arms emerged also in terms of improvement of quality of life from baseline, evaluated with Inflammatory Bowel Disease Questionnaire (IBDQ). ${ }^{24}$ Serum golimumab levels, assessed at 2, 4, and 6 weeks, respectively, were doseproportional and were directly associated with greater rates of clinical benefit.

The PURSUIT-IV trial, ${ }^{18}$ conducted from August 2007 to May 2009, evaluated the efficacy at week 6 of one single dose intravenous (IV) induction therapy with golimumab in patients with moderate-to severe UC, naïve to anti-TNFalpha and refractory or intolerant to conventional drugs. As with PURSUIT-SC, ${ }^{17}$ this study included two phases: a dose-finding Phase II to establish the dose-response relationship among three different induction regimens $(1,2$, or $4 \mathrm{mg} / \mathrm{kg}$, respectively) and a Phase III to assess real efficacy and safety of previously selected dosages. In the Phase II, a clear dose-response relationship was not observed, the highest two regimens, 2 and $4 \mathrm{mg} / \mathrm{kg}$, were selected for further development in the Phase III. However, after the analysis of all Phase II data, which revealed a lower than expected efficacy, the enrollment in the Phase III was prematurely interrupted, after the inclusion of 44 patients. The efficacy analysis, performed on all 291 patients randomized in both Phase II and III, did not show any significant difference among golimumab and placebo-treated patients in terms of clinical response, clinical, and endoscopic remission at week 6. Conversely, a greater proportion of patients actively treated with golimumab (particularly those receiving a single $2 \mathrm{mg} / \mathrm{kg}$ or $4 \mathrm{mg} / \mathrm{kg}$ infusion) experienced an improvement in their quality of life, evaluated with IBDQ. ${ }^{23}$

The comparison of these two induction studies suggested more favorable pharmacokinetics of golimumab when administered SC, probably related to a more sustained serum concentrations over the 6-week induction period, compared to one single IV infusion.

\section{Maintenance study}

After the completion of induction studies, only patients who responded to SC or IV golimumab induction, were rerandomized and enrolled in PURSUIT-M trial, ${ }^{19}$ which evaluated the efficacy of SC golimumab as long-term maintenance therapy. Four-hundred and sixty-four patients were randomized to receive $\mathrm{SC}$ golimumab $50 \mathrm{mg}, 100 \mathrm{mg}$, or placebo, respectively, every 4 weeks through 52 weeks and followed-up for 54 weeks. The study also included an open-label extension arm, including 764 patients among placebo-induction responders who maintained placebo every 4 weeks through week 52 and placebo and golimumab induction nonresponders, who received golimumab $100 \mathrm{mg}$ every 4 weeks through 52 weeks. Randomized patients were clinically evaluated using the partial Mayo Score at each visit every 4 weeks, with the addition of endoscopy (full Mayo Score) at week 30 and 54, respectively. The primary endpoint was the clinical response maintained through week 54 in golimumab induction-responders (ie, continuous clinical response $[\mathrm{CCR}]$ ). Compared to previous maintenance trials with infliximab and adalimumab, ${ }^{5-12}$ the methodology of the PURSUIT-M study has two peculiar characteristics: 1) efficacy of long-term maintenance treatment with golimumab was evaluated only in the subgroup of patients who responded to golimumab induction (SC or IV), rerandomized to golimumab or placebo; 2) the primary endpoint was CCR, that is the maintenance of constant benefit over 54 weeks, without any relapse during the year of observation, and not a single assessment at one specific time-point.

This endpoint was met in $49.7 \%$ and $47 \%$ of patients who received $100 \mathrm{mg}$ and $50 \mathrm{mg}$ of golimumab, respectively, compared with $31.2 \%$ of patients belonging to the placebo group $(P<0.001$ and $P=0.010$, respectively). Moreover, a greater proportion of patients treated with golimumab $100 \mathrm{mg}$ achieved, at both week 30 and 54, clinical remission and mucosal healing compared to placebo (27.8\% vs $15.6 \%, P=0.004$ and $42.4 \%$ vs $26.6 \%, P=0.002$, respectively; Table 2 ).

Data from post hoc sub-analysis confirmed the validity of the primary outcome, showing that patients achieving CCR through week 54 were more likely to have better clinical outcomes compared to non-CCR patients. In particular, a greater proportion of CCR patients receiving steroids at baseline, were able to stop steroids, achieved clinical and endoscopic remission and experienced a greater improvement of IBDQ outcomes. Furthermore, higher mean decreases from baseline (week 0 of PURSUIT-M study) in fecal lactoferrin and calprotectin values were recorded (only abstract available). ${ }^{24}$

In PURSUIT-M, ${ }^{19}$ serum golimumab levels were assessed before each drug administration and reached the steady-state approximately after 8 weeks from the first maintenance golimumab dose, regardless of the received induction regimen. Serum golimumab concentrations were dose-proportional, 
since golimumab treated patients, at the dose of $100 \mathrm{mg}$, had double the serum concentrations compared to golimumab treated patients at the dose of $50 \mathrm{mg}$ at each follow-up visit. Moreover, among randomized patients, higher serum levels, stratified by concentrations quartiles, were associated with better clinical outcomes.

In PURSUIT-M, the development of antibodies against golimumab through 54 weeks was lower compared to the incidence of anti-drug antibodies reported for infliximab and adalimumab (approximately 2.9\%). ${ }^{5,12}$

After the completion of 52 weeks treatment period and 54 weeks follow-up, eligible patients entered 3 year open-label long-term extension (LTE), maintaining the same golimumab doses or placebo they were taking at the end of PURSUITM study. However, during LTE, in case of disease flares on golimumab $50 \mathrm{mg}$ or placebo, patients could have their treatment modified to golimumab $100 \mathrm{mg}$. At week 104, 80.5\% of patients (157/195), previously randomized to golimumab and on maintenance with it during LTE, had a Physician's Global Assessment of $0 / 1$ and $56.4 \%$ of them (110/195) had a Physician's Global Assessment of 0 (according to an intention-to-treat analysis). Steroids were not necessary until week 104 for $88.5 \%$ of steroid-free patients at the end of week 54 of PURSUIT-M. ${ }^{25}$

\section{Medical treatment of refractory UC: the position of golimumab}

The standard treatment of patients with UC is based on a step-up approach, in which, according to disease activity and extension, more powerful and potentially more dangerous therapies are progressively added at each step. Patients could be categorized as refractory at each level of this pyramid, even though sometimes because of a suboptimal use of each specific therapy, in terms of dose, route of administration or timing. ${ }^{26}$ Biologic drugs are commonly positioned at the top of this pyramid and recommended in case of failure or intolerance of all previous therapies. However, despite current guidelines recommending thiopurines as first line immunosuppressive therapy, ${ }^{3}$ few evidence-based data have been reported to support the efficacy for patients with UC, most of them derived from clinical trials with small sample sizes, short follow-up, and performed several decades ago. ${ }^{27-30}$ Furthermore, taking into account their slow-acting profile (average 3-4 months), thiopurines cannot be considered alone for inducing disease remission. Therefore, an earlier introduction of biologics should be considered mainly for moderate to severe patients with UC, in order to spare steroids, in particular for those who develop dependence. ${ }^{31}$
In this scenario of naïve anti-TNF-alpha patients, whether already exposed to thiopurines or not, the decision on which antiTNF-alpha agent to use can be made only based on providers' personal experience, patients' preferences, costs, and safety.

At present, the primary reason for this choice, cannot be the greater effectiveness of one anti-TNF-alpha agent, because no head-to-head comparison studies among different antiTNF-alpha agents have been performed. Recently, Stidham et $\mathrm{l}^{32}$ performed a network meta-analysis, indirectly comparing the efficacy of three available anti-TNF-alpha agents for UC comparing their effectiveness over placebo in randomized controlled trials. ${ }^{5,11-12,17,19,33}$ From this analysis, no single agent seemed to be superior to the others in terms of short-term and/or long-term clinical benefit. However, this meta-analysis did not take into account the differences on disease assessments (Probert et $\mathrm{al}^{33}$ used ulcerative colitis symptom score and not Mayo Score ${ }^{22}$ ) and study designs.

Compared to the others, ${ }^{6,11,12}$ PURSUIT trials ${ }^{17-19}$ had in fact several innovative features, first, due to the two-stage rerandomization trial design with the evaluation of long-term effectiveness data only in patients who responded to induction, but also the inclusion of steroid-dependent patients and the definition of CCR.

Later on, Thorlund et al proposed a new mathematical model of network meta-analysis accounting for differences in trial design. From this analysis, as golimumab and infliximab appeared comparable in long-term clinical and endoscopic benefit, golimumab seemed to be statistically superior to adalimumab. $^{34}$

Although the validity of statistical approach adopted, to date, in our opinion, it is far too early to draw any conclusions on the superiority of one anti-TNF-alpha agent. As far as route of administration is concerned, patients need to be informed about all different available options and have the opportunity to discuss with physicians pros and cons of each one. It is a commonly noted how convenient SC administration is, in particular for young patients who are more active, need to travel, or simply do not want to feel sick coming to the hospital for an infusion. ${ }^{35}$ Compared to adalimumab, administered every other week, golimumab has the advantage of a 4 week administration, but the disadvantage of a fixed dose. Notably, to date, even though higher through levels seemed to be associated with better outcomes, ${ }^{17,19}$ it remains to be determined the benefit of golimumab dose escalation in case of partial response or loss of response. In PURSUIT-M study, ${ }^{19}$ a subgroup analysis on dose adjustment comparing secondary nonresponder patients on golimumab $50 \mathrm{mg}$ who increased to $100 \mathrm{mg}$ with those who continued receiving 
$50 \mathrm{mg}$, did not reveal any differences in terms of clinical response at week 54 .

Conversely, of note, the scheduled treatment of golimumab for rheumatological diseases consists of $50 \mathrm{mg}$ single administration every month with or without methotrexate without an initial loading dose. ${ }^{21}$ As far as rheumatoid arthritis is concerned, golimumab, in combination with methotrexate, was shown to be effective in the induction of durable symptoms' control in difficult-to-treat population, who failed disease modifying anti-rheumatic $\operatorname{drugs}^{36}$ and anti-TNF-alpha drugs. ${ }^{37}$ Similar findings have been reported in patients with refractory psoriatic arthritis ${ }^{38}$ and ankylosing spondylitis, ${ }^{39}$ for whom golimumab was effective in maintaining clinical benefit up to 60 months. Additionally, in ankylosing spondylitis, patients who had an inadequate response to golimumab 50 mg experienced an improvement of symptoms after the dose escalation up to $100 \mathrm{mg} .{ }^{39}$

\section{Safety}

In PURSUIT-M trials, ${ }^{19}$ the incidence of adverse events, adjusted for length of follow-up were comparable among golimumab and placebo randomized patients through week 54. Infections were recorded in 39\% of golimumab treated patients (120/308), but only 3.2\% (10 patients) of them were serious. Serious adverse events occurred in approximately $11 \%$ (mean value between $8.4 \%$ of golimumab $50 \mathrm{mg}$ and $14.3 \%$ of golimumab $100 \mathrm{mg}$, respectively) of golimumab treated patients $(35 / 308)$ compared to $7.7 \%$ of placebo-treated ones. Injection-site reactions were reported in only $4.5 \%$ of treated patients (totally 14 golimumab patients), none of which were serious.

Long-term safety data could be extracted from rheumatologic experiences, since golimumab has been approved for the treatment of rheumatoid arthritis, psoriatic arthritis, and ankylosing spondylitis. ${ }^{36-39}$ Golimumab safety was comparable to other anti-TNF-alpha agents, without any increase of serious adverse events, malignancies, serious infection, or injection-site reactions reported in the long-term treatment.

\section{Conclusion}

Based on all the available data, golimumab seems a valid medical option for the induction and maintenance of sustained clinical benefit in refractory patients with UC, who failed or did not tolerate conventional drugs, or were steroid-dependent. However, it could be difficult translating the results of clinical trials into daily practice, mainly because of the heterogeneity of patients in a daily clinical setting. To date, no data from "real life" regarding golimumab in UC have been published.
However, owing to encouraging results and the great interest of the scientific community for new drugs, above all, for refractory patients, we can be expect, increasing widespread use of golimumab for patients with UC.

\section{Acknowledgments}

Author AA received lecture fee(s) from Abbvie, AstraZeneca, Chiesi, Ferring, MSD, Otsuka, Takeda, Zambon; consultancy fees from Abbvie, Hospira, Lilly, MSD, Mundipharma, Sofar, and Takeda; and grant for research from MSD. Author CF has received consultancy fees from MSD. Author LG has received financial support for research from Abbvie and MSD.

\section{Disclosure}

The authors report no conflicts of interest in this work.

\section{References}

1. Sands BE, Tremaine WJ, Sandborn WJ, et al. Infliximab in the treatment of severe steroid-refractory ulcerative colitis: A pilot study. Inflammatory Bowel Dis. 2001;7:83-88.

2. Gornet JM, Couve S, Hassani Z, et al. Infliximab for refractory ulcerative colitis or indeterminate colitis: an open-label multicentre study. Aliment Pharmacol Ther. 2003;18(2):175-181.

3. Dignass A, Lindsay JO, Sturm A, et al. Second European evidence-based consensus on the diagnosis and management of ulcerative colitis part 2: current management. J Crohns Colitis. 2012;6(10):991-1030.

4. Tracey D, Klareskog L, Sasso EH, Salfeld JG, Tak PP. Tumor necrosis factor antagonist mechanisms of action: a comprehensive review. Pharmacol Ther. 2008;117(2):244-279.

5. REMICADE ${ }^{\circledR}$ (infliximab) [package insert]. Horsham, PA: Janssen Biotech, Inc.; 2013.

6. Rutgeerts P, Sandborn WJ, Feagan BG, et al. Infliximab for induction and maintenance therapy for ulcerative colitis. N Engl J Med. 2005; 353(23):2462-2247.

7. Ferrante M, Vermeire S, Fidder H, et al. Long-term outcome after infliximab for refractory ulcerative colitis. J Crohns Colitis. 2008;2(3): 219-225.

8. Armuzzi A, Pugliese D, Danese S, et al. Infliximab in steroid-dependent ulcerative colitis: effectiveness and predictors of clinical and endoscopic remission. Inflamm Bowel Dis. 2013;19(5):1065-1072.

9. Armuzzi A, Pugliese D, Danese S, et al. Long-term combination therapy with infliximab plus azathioprine predicts sustained steroid-free clinical benefit in steroid-dependent ulcerative colitis. Inflamm Bowel Dis. 2014;20(8):1368-1313.

10. HUMIRA ${ }^{\circledR}$ (adalimumab) [package insert]. North Chicago, IL: AbbVie Inc; 2015.

11. Reinisch W, Sandborn WJ, Hommes DW, et al. Adalimumab for induction of clinical remission in moderately to severely active ulcerative colitis: results of a randomised controlled trial. Gut. 2011;60(6): 780-787.

12. Sandborn WJ, van Assche G, Reinisch W, et al. Adalimumab induces and maintains clinical remission in patients with moderate-to-severe ulcerative colitis. Gastroenterology. 2012;142(2):257-265.

13. Armuzzi A, Biancone L, Daperno M, et al. Italian Group for the Study of Inflammatory Bowel Disease. Adalimumab in active ulcerative colitis: a "real-life" observational study. Dig Liver Dis. 2013;45(9):738-743.

14. Ben-Horin S, Kopylov U, Chowers Y. Optimizing anti-TNF treatments in inflammatory bowel disease. Autoimmun Rev. 2014;13(1): 24-30. 
15. Allez M, Karmiris K, Louis E, et al. Report of the ECCO pathogenesis workshop on anti-TNF therapy failures in inflammatory bowel diseases: definitions, frequency and pharmacological aspects. J Crohns Colitis. 2010;4(4):355-366.

16. Langholz E, Munkholm P, Davidsen M, Binder V. Course of ulcerative colitis: analysis of changes in disease activity over years. Gastroenterology. 1994;107:3-11.

17. Sandborn WJ, Feagan BG, Marano C, et al. PURSUIT-SC Study Group. Subcutaneous golimumab induces clinical response and remission in patients with moderate-to-severe ulcerative colitis. Gastroenterology. 2014;146(1):85-95.

18. Rutgeerts P, Feagan BG, Marano CW, et al. PURSUIT-IV study group. Randomised clinical trial: a placebo-controlled study of intravenous golimumab induction therapy for ulcerative colitis. Aliment Pharmacol Ther. 2015;42:504-514.

19. Sandborn WJ, Feagan BG, Marano C, et al. PURSUIT-Maintenance Study Group. Subcutaneous golimumab maintains clinical response in patients with moderate-to-severe ulcerative colitis. Gastroenterology. 2014;146(1):96-109.

20. Shealy D, Cai A, Staquet K, et al. Characterization of golimumab, a human monoclonal antibody specific for human tumor necrosis factor $\alpha$. MAbs. 2010;2(4):428-439.

21. SIMPONI ${ }^{\circledR}$ (golimumab) [package insert]. Horsham, PA: Janssen Biotech, Inc.; 2015.

22. Schroeder KW, Tremaine WJ, Ilstrup DM. Coated oral 5-aminosalicylic acid therapy for mildly to moderately active ulcerative colitis. A randomized study. $N$ Engl J Med. 1987;317:1625-1629.

23. Irvine EJ, Feagan B, Rochon J, et al. Quality of life: a valid and reliable measure of therapeutic efficacy in the treatment of inflammatory bowel disease. Canadian Crohn's Relapse Prevention Trial Study Group. Gastroenterology. 1994;106:287-296.

24. Colombel J, Reinisch W, Gibson P, et al. Clinical outcomes in continuous clinical responders with moderately to severely active ulcerative colitis: sub-analysis from the PURSUIT-SC MANTEINANCE Study. United European Gastroenterol J. 2014;2(S1):A376.

25. Feagan B, Gibson W, Reinisch W, et al. Long-term safety and efficacy of Golimumab in patients with moderately to severely active ulcerative colitis: results from the PURSUIT-SC maintenance study extension. Can J Gastroenterol. 2015;29(SA):A263.

26. Panaccione R, Rutgeerts P, Sandborn WJ, Feagan B, Schreiber S, Ghosh S. Review article: treatment algorithms to maximize remission and minimize corticosteroid dependence in patients with inflammatory bowel disease. Aliment Pharmacol Ther. 2008;28(6):674-688.

27. Jewell DP, Truelove SC. Azathioprine in ulcerative colitis: an interim report on a controlled therapeutic trial. Br Med J. 1972;1(5802): 709-712.
28. Caprilli R, Carratù R, Babbini M. Double-blind comparison of the effectiveness of azathioprine and sulfasalazine in idiopathic proctocolitis. Preliminary report. Am J Dig Dis. 1975;20(2):115-120.

29. Sood A, Midha V, Sood N, Kaushal V. Role of azathioprine in severe ulcerative colitis: one-year, placebo-controlled, randomized trial. Indian J Gastroenterol. 2000;19(1):14-16.

30. Ardizzone S, Maconi G, Russo A, Imbesi V, Colombo E, Bianchi Porro G. Randomised controlled trial of azathioprine and 5-aminosalicylic acid for treatment of steroid dependent ulcerative colitis. Gut. 2006; 55(1):47-53

31. Dignass A, Eliakim R, Magro F, et al. European evidence-based consensus on the diagnosis and management of ulcerative colitis part 1 definitions and diagnosis. J Crohns Colitis. 2012;6:965-990.

32. Stidham RW, Lee TC, Higgins PD, et al. Systematic review with network meta-analysis:the efficacy of anti-tumour necrosis factor-alpha agents for the treatment of ulcerative colitis. Aliment Pharmacol Ther. 2014;39(7):660-671.

33. Probert CS, Hearing SD, Schreiber S, Kühbacher T, et al. Infliximab in moderately severe glucocorticoid resistant ulcerative colitis: a randomised controlled trial. Gut. 2003;52(7):998-1002.

34. Thorlund K, Druyts E, Toor K, Mills EJ. Comparative efficacy of golimumab, infliximab, and adalimumab for moderately to severely active ulcerative colitis: a network meta-analysis accounting for differences in trial designs. Expert Rev Gastroenterol Hepatol. 2015;9(5):693-700.

35. Sylwestrzak G, Liu J, Stephenson JJ, Ruggieri AP, DeVries A Considering patient preferences when selecting anti-tumor necrosis factor therapeutic options. Am Health Drug Benefits. 2014;7(2):71-81.

36. Keystone EC, Genovese MC, Hall S, et al. Golimumab in patients with active rheumatoid arthritis despite methotrexate therapy: results through 2 years of the GO-FORWARD study extension. J Rheumatol. 2013;40(7):1097-1103.

37. Smolen JS, Kay J, Doyle M, et al. Golimumab in patients with active rheumatoid arthritis after treatment with tumor necrosis factor $\alpha$ inhibitors: findings with up to five years of treatment in the multicenter, randomized, double-blind, placebo-controlled, phase 3 GO-AFTER study. Arthritis Res Ther. 2015;17:14.

38. Kavanaugh A, McInnes IB, Mease P, et al. Clinical efficacy, radiographic and safety findings through 5 years of subcutaneous golimumab treatment in patients with active psoriatic arthritis: results from a long-term extension of a randomised, placebo-controlled trial (the GO-REVEAL study). Ann Rheum Dis. 2014;73(9):1689-1694.

39. Deodhar A, Braun J, Inman RD, et al. Golimumab administered subcutaneously every 4 weeks in ankylosing spondylitis:5-year results of the GO-RAISE study. Ann Rheum Dis. 2015;74(4):757-761.
Drug, Healthcare and Patient Safety

\section{Publish your work in this journal}

Drug, Healthcare and Patient Safety is an international, peer-reviewed open-access journal exploring patient safety issues in the healthcare continuum from diagnostic and screening interventions through to treatment, drug therapy and surgery. The journal is characterized by the rapid reporting of reviews, original research, clinical, epidemiological and

\section{Dovepress}

post-marketing surveillance studies, risk management, health literacy and educational programs across all areas of healthcare delivery. The manuscript management system is completely online and includes a very quick and fair peer-review system. Visit http://www.dovepress.com/ testimonials.php to read real quotes from published authors. 